\title{
Sistem Kendali Penggerak Motor Stepper Pada Orbital Welding Menggunakan Perangkat Lunak LabVIEW
}

\author{
Budi Suhendro $^{1}$, Landung Malik Antoro ${ }^{2}$, Suroso ${ }^{3}$ \\ ${ }^{1,3}$ Sekolah Tinggi Teknologi Nuklir - Badan Tenaga Nuklir Nasional, \\ Jl. Babarsari Kotak Pos 6101 YKBB Yogyakarta \\ Email: bsuhendro@batan.co.id
}

\begin{abstract}
Orbital welding motion in welding for joining pipes or cylinders, has a circular or circular motion that includes horizontal or vertical motion. The orbital velocity for a welding gun is expected to have a steady and stable velocity. Therefore, the aim of this research is to design a control system to control the movement of a stepper motor in orbital welding using LabVIEW software and Arduino Mega 2560 hardware, , this system requires LabVIEW software and hardware in the form of an Arduino Mega 2560, and a TB6600 driver to control the movement of the actuator or stepper motor. The movement of the stepper motor in this welding is divided into 2 segments. Segment 1 moves from an angle of $0^{\circ}-180^{\circ}$ in a clockwise motion and segment 2 moves from an angle of $0^{\circ}-180^{\circ}$ in a counter clockwise motion. In this study, 10 variations of speed were used to determine the appropriate movement or speed for circular welding. This speed variation starts from a frequency of 1000-5500 Hz. From the RSME test that has been carried out, the results obtained with low error values at frequencies of $1000 \mathrm{~Hz}$ and $1500 \mathrm{~Hz}$ with error values of 0.325 and 0.175 . Meanwhile, from the test of average speed or RPM, the results obtained successively from the frequency of $1000 \mathrm{~Hz}-5500 \mathrm{~Hz}$, namely $3 \mathrm{rpm}, 6 \mathrm{rpm}, 6,024 \mathrm{rpm}, 8.975 \mathrm{rpm}, 9.897$ rpm, $12.057 \mathrm{rpm}, 15.09 \mathrm{rpm}, 14.915 \mathrm{rpm}$, and $17.93 \mathrm{rpm}$.
\end{abstract}

Keywords: System Control, Orbital, Welding Gun, Stepper Motor, RSME

\begin{abstract}
Abstrak: Gerak pengelasan orbital pada pengelasan untuk penyambungan pipa atau silinder, mempunyai arah gerak mengitari atau melingkar yang mencakup gerak horizontal atau gerak vertikal. Kecepatan gerak orbital untuk sebuah welding gun diharapkan mempunyai kecepatan yang tetap dan stabil. Oleh karena itu, tujuan dari penelitian ini adalah membuat rancangbangun sistem kontrol pengendalian pergerakan motor stepper pada orbital welding menggunakan software LabVIEW dan hardware Arduino Mega 2560. Sebagai sumber tenaga gerak dari aktuator berupa motor stepper, agar dapat mengendalikan kecepatan dan arah sesuai dengan kebutuhan gerak dari motor, sistem ini membutuhkan perangkat lunak LabVIEW dan perangkat keras berupa Arduino Mega 2560, dan driver TB6600 untuk mengatur gerakan pada aktuator atau motor stepper. Pergerakan motor stepper dalam pengelasan ini terbagi menjadi 2 segment. Segment 1 bergerak dari sudut $0^{\circ}-180^{\circ}$ dengan pergerakan searah jarum jam dan segment 2 bergerak dari sudut $0^{\circ}-180^{\circ}$ dengan pergerakan berlawanan arah jarum jam. Pada penelitian ini dilakukan 10 variasi kecepatan yang berguna untuk menentukan pergerakan atau kecepatan yang sesuai untuk pengelasan melingkar. Variasi kecepatan ini dimulai dari frekuensi 1000-5500 Hz. Dari pengujian RSME yang telah dilakukan didapatkan hasil dengan nilai error yang rendah pada frekuensi $1000 \mathrm{~Hz}$ dan $1500 \mathrm{~Hz}$ dengan nilai error sebesar 0,325 dan 0,175. Sedangkan dari pengujian kecepatan atau RPM rata-rata didapatkan hasil secara berturut-turut dari frekuensi $1000 \mathrm{~Hz}-$ $5500 \mathrm{~Hz}$ yaitu $3 \mathrm{rpm}, 6 \mathrm{rpm}, 6,024 \mathrm{rpm}, 8,975 \mathrm{rpm}, 9,897 \mathrm{rpm}, 12,057 \mathrm{rpm}, 15,09 \mathrm{rpm}, 14,915 \mathrm{rpm}$, dan $17,93 \mathrm{rpm}$.
\end{abstract}

Kata kunci: Sistem Kendali, Orbital, Welding Gun, Motor Stepper, RSME

\section{PENDAHULUAN}

Welding adalah salah satu teknik penyambungan logam dengan cara mencairkan sebagian logam induk dan logam pengisi dengan atau tanpa tekanan dan dengan atau tanpa logam 
penambah dan menghasilkan sambungan yang kontinyu. Pada prinsipnya proses pengelasan adalah menyambugkan dua atau lebih komponen, lebih tepat ditujukan untuk merakit beberapa komponen menjadi satu bentuk mesin. Untuk menyambungkan pipa satu dengan yang lainnya dibutuhkan las untuk melakukan pengelasan (Patro and Pradhan, 2018).

Di Indonesia masih sering dijumpai pengelasan dengan tenaga konvensional atau tenaga manusia. Untuk meminimalisir kesalahan dari welder dan mendukung industri 4.0 maka dikembangkanlah las otomatis khususnya pada pipa orbital. Orbital welding atau las otomatis pipa adalah sebuah alat yang diciptakan manusia untuk memudahkan pekerjaan manusia saat ingin menyambungkan dua pipa atau lebih menjadi satu rangkaian (Hartono and Nauval Fauzi, 2016). Pengembangan alat ini diharapkan dapat membantu menjadi alat bantu pengelasan pipa otomatis sebagai alat penunjang untuk memudahkan pekerjaan pada proses pengelasan yang selama ini beroperasi secara manual. Alat ini dirancang dan dibuat untuk meningkatkan efisiensi serta mampu memudahkan proses pengelasan pipa bagi para pengguna tanpa membutuhkan operator (ahli welder) (Bintoro and Yanpurnadi, 2014).

Pada penelitian ini dikembangkan pengendalian motor stepper menggunkan perangkat lunak LabVIEW. Hal ini dikarenakan software LabVIEW memiliki kelebihan yaitu dapat memprogram tanpa menggunakan bahasa pemrograman seperti biasa, namun dipermudah dengan metode pemrograman akusisinya berbasis visual. Selain itu, kelebihan LabVIEW ialah user-interface pada hasil kerja yang dapat didesain sendiri sehingga memberi nilai tambah hasil kerja kita dari segi tampilan (National Instruments, 2003). Selain menggunakan software LabVIEW, pada penelitian ini juga menggunakan hardware Arduino. Mengapa memilih menggunakan Arduino karena hardware ini mempunyai kelebihan dari hardware lainnya. Kelebihan dari hardware tersebut yaitu pengoperasiannya yang mudah, memiliki modul-modul tambahan yang lengkap, bahasa pemograman yang user friendly, referensinya banyak, dan semua software pendukung bersifat open source serta pada mikrokontroler Arduino memiliki fitur untuk berkomunikasi dengan komputer pribadi (PC) melalui komunikasi serial sehingga board arduino dapat dijadikan jembatan antara komputer dan aktuatornya (Ismail and Risdianto, 2015).

Dan pada penelitian ini dilakukan pengontrolan pada pergerakan motor stepper untuk menggerakan welding gun atau torch. Pergerakan motor stepper dalam pengelasan ini terbagi menjadi 2 segment. Segmen 1 bergerak dari sudut $0^{\circ}-180^{\circ}$ dengan pergerakan searah jarum jam dan segment 2 bergerak dari sudut $0^{0}-180^{\circ}$ dengan pergerakan berlawanan arah jarum jam dengan 4 kali sesi. Sesi pertama motor menggerakkan torch searah jarum jam dari sudut $0^{0}$ $180^{\circ}$. Sesi kedua motor menggerakan torch berlawanan arah jarum jam dari $180^{\circ}-0^{\circ}$ untuk menggerakkan torch kembali ke sudut $0^{0}$. Sesi ketiga menggerakan torch berlawanan arah jarum jam dari sudut $0^{0}-180^{\circ}$. Sesi keempat motor menggerakan torch berlawanan arah jarum jam dari $180^{\circ}-0^{\circ}$ untuk menggerakkan torch kembali ke sudut $0^{\circ}$. Untuk parameter-parameter las seperti arus, tegangan, dan elektorda las dilakuakan secara manual. Pada penelitian ini mengusulkan untuk membuat sebuah sistem kendali pada orbital welding menggunakan perangkat lunak LabVIEW untuk menggerakkan motor stepper.

\section{METODE PENELITIAN}

Berikut gambar metode tahapan alur penelitian yang telah dilakukan sebagaimana ditunjukkan pada Gambar 1. 


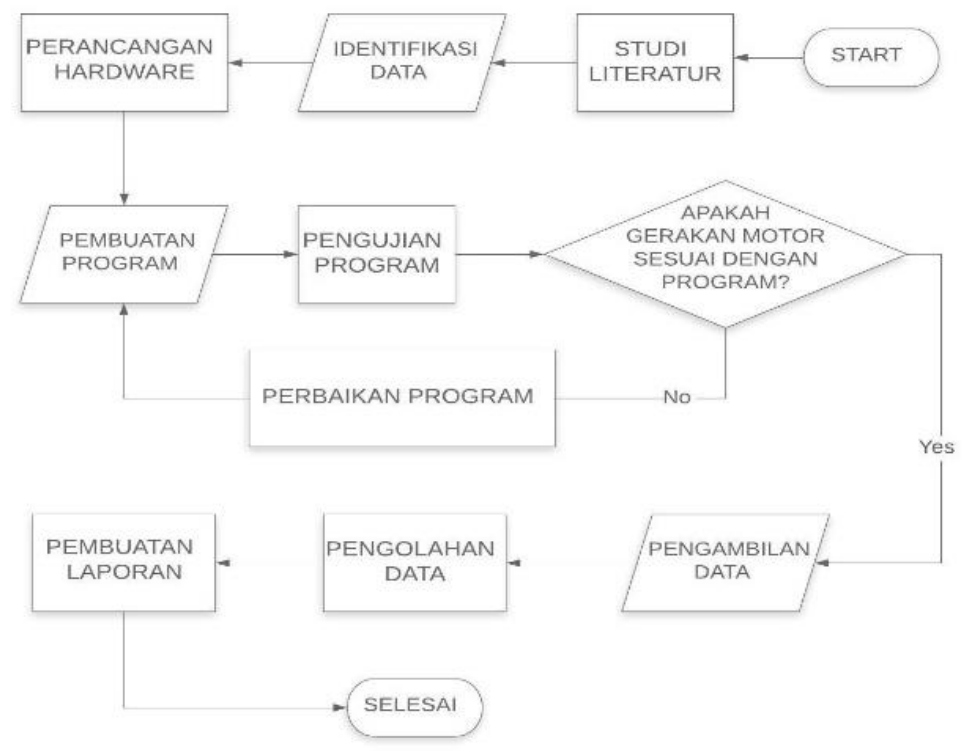

Gambar 1. Diagram Alir Penelitian

\subsection{Identifikasi Masalah}

Pada langkah ini dilakukan pengumpulan data terkait dengan pemrogram dengan menggunakan LabVIEW. Pengumpulan data ini berupa motor stepper yang digunakan beserta driver dan power supply yang akan digunakan. Pada masalah pertama yang harus ditentukan adalah penentuan jenis motor berdasarkan beban total alat welding gun.

Sehingga dibutuhkan torsi motor untuk sebesar 1,5 N.m untuk menggerakkan gear dan welding gun sebesar $8 \mathrm{~kg}$. Sehingga didapatkan jenis motor stepper karena motor ini dapat diatur kecepatan motor untuk kebutuhan pengelasan. Untuk jenis motor stepper yang digunkan adalah motor stepper NEMA 23 57HS8230A4 karena memiliki torsi melebihi torsi yang dibutuhkan yaitu 2,2 N.m. Untuk mengontrol motor tersebut dibutuhkan sebuah driver untuk menggerakkannya. Fungsi driver tersebut adalah untuk mengatur arus dan mengatur jumlah step yang dikirimkan dari driver ke motor stepper. Karena pada motor stepper tersebut membutuhkan arus sebesar 3A maka dibutuhkan driver motor TB6600 karena pada driver tersebut mempunyai arus maksimum sebesar 5A. Karena pada penelitian ini hanya simulasi maka digunakan motor stepper nema 17HS3401.

\subsection{Perancangan Hardware}

Pada langkah ini dilakukan perancangan komponen pada mesin orbital seperti perancangan Arduino, motor stepper dengan drivernya dan interface antara Arduino dan LabVIEW. Langkah pertama yang dilakukan adalah melakukan identifikasi sinyal input untuk Arduino dan driver TB6600. Berikut identifikasi pin ardunio beserta driver TB6600 seperti pada tabel 1: 
Tabel 1. Identifikas pin arduino beserta driver TB6600

\begin{tabular}{lll}
\hline Pin Arduino & Pin Driver & \multicolumn{1}{c}{ Kepala Kolom } \\
\hline D0 & ENA- & $\begin{array}{l}\text { Pin masukan input untuk driver } \\
\text { motor Stepper } \\
\text { Pin masukan input untuk driver } \\
\text { motor Stepper }\end{array}$ \\
D2 & DIR- & $\begin{array}{l}\text { Pin masukan input untuk driver } \\
\text { motor Stepper } \\
\text { Power Supply } \\
\text { VCC }\end{array}$ \\
PUL- & VCC & Ground \\
\hline
\end{tabular}

Setelah didapatkan input untuk motor stepper kemudian dilakukan pembuatan wiring diagram alur perakitan awal sistem elektronik berdasarkan tabel yang telah dibuat. Berikut blok diagram perakitan alat seperti pada gambar 2 sebagai berikut:

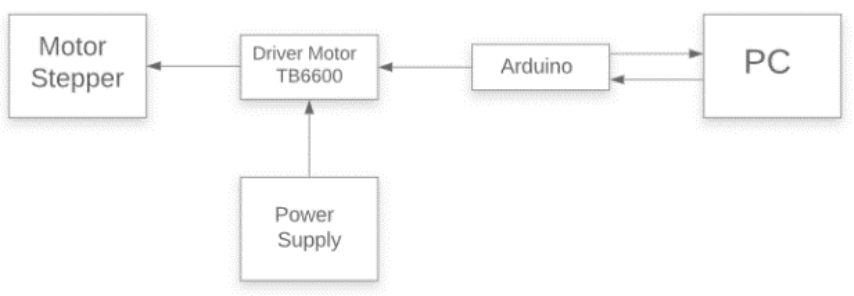

Gambar 2. Blok Diagram Perakitan Alat

\subsection{Pembuatan Program}

Pada pembuatan program ini dilakukan setelah perakitan hardware telah selesai dilakukan. Pada langkah ini dilakukan pemasukkan program untuk mengontrol kecepatan motor stepper dengan menggunakan perangkat keras Arduino. Sebelum dilakukan pemrograman pada motor, dilakukan pembuatan diagram alir program sistem pada gambar 3 sebagai berikut:

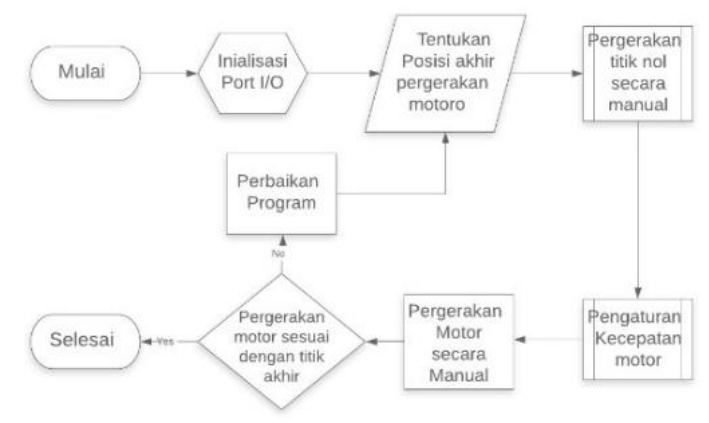

Gambar 3. Diagram Alir Program

Pada diagram alir tersebut dapat diketahui bahwa diawali dengan inialisasi port I/O pada Arduino. Setalah dilakukan inialisasi pada Arduino kemudian dilakukan penentuan posisi terakhir pergerakan motor dimana motor tersebut akan menggerakkan torch yang akan melakukan pengelasan pada pipa. Kemudian dilakukan penentuan titik nol atau posisi awal pergerakan motor, untuk posisi pergerakan motor ini akan diletakan pada posisi $0^{\circ}$ pada pipa. Apabila titik nol sudah didapatkan kemudian dilakukan simulasi apakah pergerakan motor sesuai dengan titik akhir yang telah ditentukan yaitu pada posisi $180^{\circ}$. Apabila pergerakan tidak 
sesuai maka akan dilakukan perbaikan program. Selanjutnya pada program LabVIEW dapat dilakukan pengaturan kecepatan motor dengan mengatur frekuensi masukan tiap kecepatan yang dibutuhkan. Pada program LabVIEW terdapat alogaritma model kecepatan yang ditunjukkan pada gambar 4 yang ditunjukkan dibawah ini:

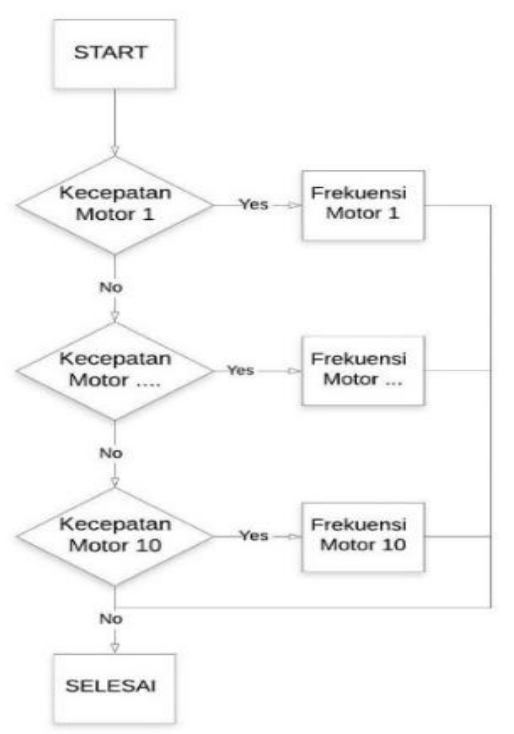

Gambar 4. Diagram Alir Kecepatan Motor

Pada gambar 4 diketahui terdapat 10 model kecepatan yang akan divariasikan frekuensi. Kecepatan putaran motor bergantung pada besar kecilnya frekuensi yang akan diatur. Variasi kecepatan motor ini dimulai dari frekuensi $1000 \mathrm{~Hz}$ sampai $5500 \mathrm{~Hz}$. Beda frekuensi antara kecepatan motor 1 dengan yang lain yaitu $500 \mathrm{~Hz}$.

Pada pengaturan titik awal atau titik nol agar torch berada pada sudut $0^{0}$ pada pipa dilakukan dengan menekan tombol $\mathrm{X}+$ dan $\mathrm{X}-$. Berikut diagram alir pergerakan manual pada progam seperti gambar 5:

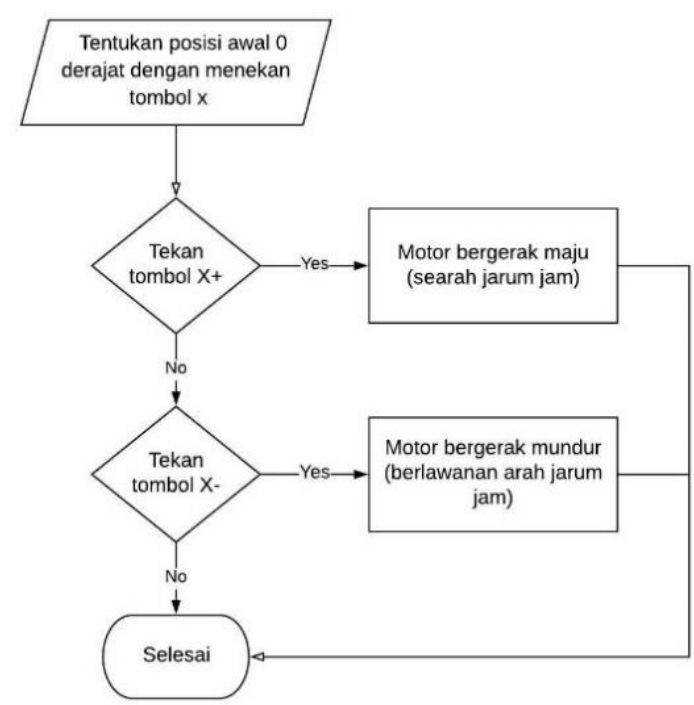

Gambar 5. Diagram Alir Pergerakan Manual

Pada gambar diatas merupakan alogaritma pergerakan torch secara manual. Pengaturan titik awal atau titik nol dapat dilakukan dengan menekan tombol X- untuk menggerakan motor stepper bergerak 
mundur atau berlawanan arah jarum jam. Tombol X+ digunakan untuk menggerakan motor stepper bergerak maju atau searah jarum jam.

\subsection{Pengujian Program}

Pada pengujian ini dilakukan pengujian program sistem mekanik dan elektrik. Apabila program berjalan tidak baik, maka harus dilakukan perbaikan pada program yang telah dibuat. Jika program berjalan sesuai dengan keinginan, maka selanjutnya dilakukan pengambilan data.

Dan pada pengujian ini dilakukan juga apakah motor bergerak sesuai dengan program yang telah dibuat. Terdapat 2 pengujian yang akan dilakukan pada tahap ini. Pada pengujian ini memiliki keutamaan yang sama yaitu tentang pergerakan motor. Yang pertama, secara manual jika tombol $\mathrm{X}+$ ditekan maka motor akan bergerak searah jarum jam. Dan yang kedua, secara manual jika tombol X- ditekan maka motor akan bergerak berlawanan arah jarum jam. Yang ketiga, jika tombol otomatis ditekan maka motor akan berjalan sesuai dengan program dengan 4 indeks atau sesi. Sesi pertama, motor menggerakan torch searah jarum jam dari sudut $0^{\circ}-180^{\circ}$. Sesi kedua, motor menggerakan torch berlawanan arah jarum jam dari sudut $180^{\circ}-0^{\circ}$ sehingga kembali pada sudut $0^{0}$. Sesi ketiga, motor menggerakan torch berlawanan arah jarum jam dari sudut $0^{0}-180^{\circ}$. Sesi kedua, motor menggerakan torch searah jarum jam dari sudut $180^{\circ}-0^{\circ}$ sehingga kembali pada sudut $0^{0}$ Apabila pada motor tersebut bergerak tidak sesuai dengan program, maka harus dilakukan perbaikan program.

Pada pengujian kecepatan mempunyai tujuan yaitu untuk mengetahui spesifikasi dari motor yang digunakan. Pengujian ini dilakukan dengan mengukur putaran motor pada setiap frekuensi secara manual pada motor stepper selama 1 menit. Pengujian ini hanya dilakukan pada tombol $\mathrm{X}+$.

\subsection{Pengambilan Data}

Dilakukan pengambilan data setelah Arduino interface dengan menggunakan program LabVIEW. Pengambilan data ini dilakukan sebanyak sepuluh kali untuk setiap model kecepatan yang diuji.

Data yang diuji yaitu data posisi pipa material pipa pada sudut $00-1800$ searah jarum jam dan sudut 00-1800 berlawanan jarum jam yang menghasilkan pergerakan motor stepper sesuai dengan input sinyal frekuensi dan dilakukan pengujian sebanyak 10 kali. Sehingga didapatkan selisih sudut antara pergerakan motor pertama dengan pergerakan motor kesepuluh. Kemudian hasil tersebut dikuadratkan dan dibagi dengan jumlah data yaitu 10. Setelah mendapatkan hasilnya maka hasil tersebut, maka data tersebut diolah untuk menghasilkan nilai RSME.

\subsection{Pengolahan Data}

Dilakukan pengolahan data untuk menentukan error pada setiap model kecepatan yang diujikan. Pengolahan data ini dalam bentuk grafik sehingga dapat ditentukan model kecepatan yang efektif untuk dilakukan proses pengelasan orbital.

Pengolahan data ini dilakukan dengan pengujian $R S M E$. Pengujian ini dilakukan untuk mendapatkan nilai keakuratan pada waktu yang didapatkan untuk sekali pengujian terhadap pengujian ke 1 samapi 10. Data tersebut kemudian diolah dengan menggunakan rumus $R S M E$ untuk mendapatkan nilai error dari tiap model kecepatan. Untuk pengolahan data pada kecepatan motor atau $R P M$ dan arus pada motor stepper hanya dicari nilai rata-rata dengan cara dibagi 10 pada setiap data model kecepatan dan juga pada arus. 


\subsection{Pembuatan Laporan}

Setelah pengambilan data dilakukan dan hasil dari analisa telah didapatkan maka dilakukan penyusunan terhadap hasil yang didapatkan. Pembuatan laporan ilmiah ini bertujuan untuk melaporkan, mempertanggungjawabkan dan mendokumentasikan penelitian yang telah dilakukan.

\section{HASIL DAN PEMBAHASAN}

\subsection{Bentuk Tampilan Box Pembungkus Komponen}

Terdapat dua tampilan box pembungkus komponen. Yang pertama gambar 6 yang merupakan hasil desain box pembungkus komponen beserta komponen yang telah disambungkan.

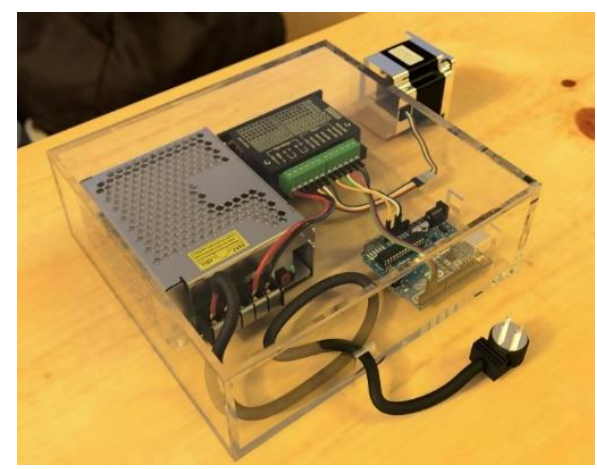

Gambar 6. Desain Box Pembungkus Beserta Komponen

Pada gambar 6 tersebut merupakan desain box pembungkus komponen dengan dimensi $25 \times 25 \times 10 \mathrm{~cm}$. Untuk bahan pembuatan pada desain tersebut adalah akrilik. Yang kedua gambar 7 merupakan box pembungkus yang telah dilakukan perakitan sesuai dengan desain yang telah dibuat. Berikut gambar 7 tersebut:

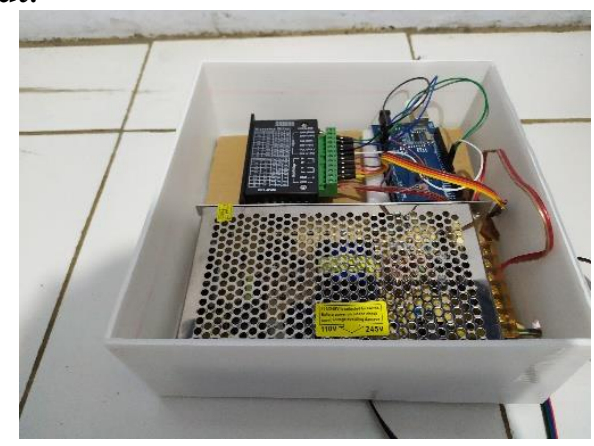

Gambar 7. Bentuk Box Pembungkus Komponen

Pada gambar 7 tersebut merupakan box pembungkus komponen yang berguna untuk meletakkan alat kontrol pada penggerak torch pada alat orbital welding. Seperti dimensi pada desain box, pada bentuk box tersebut yaitu $25 \times 25 \times 10 \mathrm{~cm}$ dengan bahan impraboard.

\subsection{Bentuk Tampilan Interface pada LabVIEW}

Berikut dapat dilihat pada gambar dibawah ini yaitu gambar 8 yaitu hasil interface pada LabVIEW: 


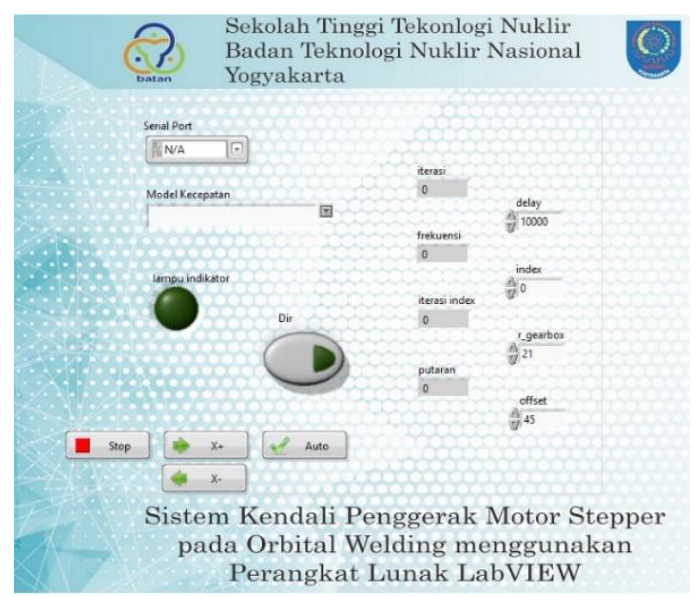

Gambar 8. Gambar Tampilan Interface pada LabVIEW

Dapat dilihat pada gambar tersebut terdapat 4 tombol yaitu tombol X+, X-, Stop dan Auto. Tombol $\mathrm{X}+$ dan $\mathrm{X}$ - berfungsi untuk mengatur posisi awal yaitu $0^{0}$ dengan pergerakan pada tombol $\mathrm{X}+$ yaitu pergerakan searah jarum jam sedangkan tombol $\mathrm{X}$ - yaitu pergerakan berlawanan arah jarum jam. Pada tombol stop berfungsi untuk menghentikan pergerakan motor atau untuk menghentikan program dan tombol auto yaitu berfungsi untuk menggerakan program atau motor stepper secara otomatis. Pada serial port yaitu port interface antara arduino dan LabVIEW dan pada kolom model kecepatan adalah kolom pemilihan model kecepatan yang akan digunakan.

\subsection{Hasil Pengujian RSME}

Pengujian posisi sebenarnya dengan posisi akhir dengan menggunakan 10 model kecepatan ini bertujuan untuk mencari model kecepatan yang stabil dalam melakukan pengelasan dan digunakan untuk menganalisa dengan pengujian RSME untuk mencari nilai error pada setiap model kecepatan Pada model kecepatan tersebut hanya dibedakan masukan frekuensi untuk memutar motor stepper dari frekuensi 1000-5500 Hz. Semakin tinggi nilai frekuensi atau masukan untuk memutar motor, maka semakin cepat pula motor akan berputar.

Tabel 2. Hasil pengujian kecepatan model kecepatan 1-10

\begin{tabular}{ccccccccccc}
\hline \multirow{2}{*}{ No } & \multicolumn{10}{c}{ Mode Kecepatan (RPM) } \\
\cline { 2 - 11 } & 1 & 2 & 3 & 4 & 5 & 6 & 7 & 8 & 9 & 10 \\
\hline 1 & 3 & 6,01 & 6,02 & 8,94 & 8,72 & 11,94 & 12 & 14,91 & 14,69 & 17,66 \\
2 & 3 & 6 & 6 & 9 & 8,75 & 11,86 & 12,016 & 15,01 & 15,02 & 18 \\
3 & 3 & 6 & 6,02 & 9,02 & 9 & 11,94 & 12,05 & 15,13 & 14,88 & 18,05 \\
4 & 2,98 & 6,01 & 6,05 & 8,95 & 8,83 & 12 & 12,01 & 15,13 & 15 & 18,01 \\
5 & 2,98 & 6,01 & 6,05 & 8,95 & 8,98 & 11,98 & 12,11 & 15,22 & 15 & 17,67 \\
6 & 3,01 & 6 & 6 & 9,11 & 8,86 & 11,94 & 12 & 15 & 14,58 & 18 \\
7 & 3 & 6 & 6 & 8,83 & 8,95 & 11,94 & 12,06 & 15,11 & 15,02 & 17,89 \\
8 & 3,01 & 6 & 6 & 9,01 & 9 & 11,91 & 12,22 & 15,13 & 15,01 & 18 \\
9 & 3,01 & 5,98 & 6,05 & 9 & 8,91 & 11,95 & 12,11 & 15,01 & 14,94 & 18,11 \\
10 & 3 & 5,97 & 6,05 & 8,94 & 8,97 & 12,05 & 12 & 15,25 & 15,01 & 17,91 \\
\hline Rata- & 3 & 6 & 6,024 & 8,975 & 8,897 & 11,95 & 12,057 & 15,09 & 14,915 & 17,93 \\
Rata & & & & & & & \\
\hline
\end{tabular}


Pengujian kecepatan setiap model kecepatan dilakukan untuk mengetahui kecepatan atau RPM pada motor stepper dengan model kecepatan 1-10. Seperti pembahasan sebelumnya, diketahui semakin tinggi nilai frekuensinya, maka semakin tinggi pula kecepatan atau RPM pada motor stepper. Hal ini diketahui karena semakin tinggi masukan motor yaitu frekuensi maka semakin banyak pula sinyal yang dikirimkan dari mikrokontroller kepada motor stepper.

\subsection{Hasil Pengujian Arus Motor}

Tabel 3. Hasil pengujian arus motor model kecepatan 1-10

\begin{tabular}{ccccccccccc}
\hline \multirow{2}{*}{ No } & \multicolumn{10}{c}{ Model Kecepatan (Arus) } \\
\cline { 2 - 11 } & 1 & 2 & 3 & 4 & 5 & 6 & 7 & 8 & 9 & 10 \\
\hline 1 & 0,2 & 0,2 & 0,2 & 0,2 & 0,2 & 0,2 & 0,2 & 0,2 & 0,2 & 0,2 \\
\hline
\end{tabular}

Pada pengujian ini dilakukan untuk mengukur arus pada motor stepper. Berdasarkan tabel 13 diketahui bahwa pada pengujian arus motor stepper menggunakan driver TB6600 pada model kecepatan 1-10 mempunyai arus yang sama yaitu 0,2 A.

\section{KESIMPULAN}

Dari hasil penelitian yang telah dilakukan bahwasannya telah dapat dirancang sistem kontrol penggerak motor stepper pada alat orbital welding menggunakan mikrokontroller arduino dan perangkat lunak LabVIEW dengan box untuk meletakkan komponen alat orbital welding. Untuk program penggerak motor tersebut telah dilakukan pembuatan menggunakan perangkat lunak LabVIEW dengan gerakan torch atau pengelasan dibagi menjadi dua. Pada pergerakan pengelasan pertama, pengelasan dilakukan searah jarum jam dari sudut $0^{0}-180^{\circ}$ sedangkan pada pergerakan pengelasan kedua, pengelasan dilakukan berlawanan arah jarum jam dari sudut $0^{0}$ $180^{\circ}$.

Dari pengujian yang telah dilakukan yaitu pengujian antara posisi sudut sebenarnya dengan posisi sudut akhir telah dilakukan untuk mengetahui error dengan menggunakan 10 model kecepatan. Dengan perhitungan RSME diperoleh hasil pada model kecepatan 1 yaitu 0.325 , model kecepatan 2 yaitu 0.175 , model kecepatan 3 yaitu 2.5 , model kecepatan 4 yaitu 2.575 , model kecepatan 5 yaitu 2.5, model kecepatan 6 yaitu 0.725 , model kecepatan 7 yaitu 1.7 , model kecepatan 8 yaitu 1.9, model kecepatan 9 yaitu 3.45 dan model kecepatan 10 yaitu 1.025. Untuk arus dan RPM rata-rata diperoleh pada model kecepatan 1 yaitu $3 \mathrm{rpm}$, model kecepatan 2 yaitu $6 \mathrm{rpm}$, dan model kecepatan 3 yaitu 6,024 rpm, model kecepatan 4 yaitu 8,975 rpm, model kecepatan 5 yaitu 8,897 rpm, dan model kecepatan 6 yaitu 11,95 rpm, model kecepatan 7 yaitu 12,057 rpm, model kecepatan 8 yaitu 15,09 rpm, dan model kecepatan 9 yaitu 14,915 rpm, dan pada model kecepatan 10 yaitu 17,93 rpm. Sedangkan pada pengujian arus pada model kecepatan 1-10 mempunyai besaran yang sama yaitu 0,2 A.

\section{SARAN}

Dari penelitian yang telah dilakukan terdapat beberapa saran, yaitu:

- Pada program yang telah dibuat hanya dilakukan simulasi terkait pergerakan motor stepper dan karena pandemi covid 19 ini kami belum dapat mempratekannya pada welding gun atau torch yang sesungguhnya sehingga belum diketahui berapa kecepatan yang pas untuk penggerak welding gun agar diperoleh hasil lasan yang rigid dan seragam, maka pada penelitian selanjutnya diharapkan dapat mementukan kecepatan yang pas untuk dilakukan pengelasan orbital. 
- Untuk pengembangan kedepannya, untuk pengukuran sudut putaran bisa dilakukan secara otomatis.

\section{DAFTAR PUSTAKA}

Patro R and Pradhan S. K," Finite element simulation and optimization of orbital welding process parameters," in International Conference on Material Manufacturing and Modelling, 2017. ISMMM, 2017, pp. 12886-12900.

P. Hartono and M. N. Fauzi, "pengendali otomatis 3-axis berbasis PC pada simulasi proses las," Metal Indonesia, vol.36, pp. 8-15,2016.

Riswanda, W. M. Bintoro, and Duduy Y," desain dan pembuatan alat bantu pengelasan pipa pada proses GMAW dengan variasi kecepatan menggunakan sistem transmisi," Industrial Research Workshop National Seminar, vol.5, pp. 235-238

National Instruments," labview user manual", 2003.

K. Ismail and Agus R,"desain pengamatan port mikrokontrol arduino dengan protokol firmata pada antarmuka komputer yang berbasiskan labview," Lembaga Ilmu Pengetahuan Indonesia.

T. A. Kurniawan," perancangan sistem pengendalian lampu berbasis SMS gateway dengan mikrokontroler atmega 8535," in Seminar Nasional Inovasi Teknologi, 2017. SNITek 2017.

K. Ogata, Teknik Kontrol Automatik, jilid 1, Erlangga, 1991.

P. Kah, M. Sharestha, E. Hiltunen, and J. Martikanien," robotic arc welding sensors and programming in industrial applications," International Jurnal of Mechanical and Materials Engineering, vol.10, pp. 13-29

S. A. Sigiro, T. Tamba, M. Sitepu, dan Andi S," instrumentasi virtual menggunakan labview dan soundcard," Unviersitas Sumatra Utara, 2015

J. Arifin, L. N. Zulia, dan Hermawansyah," perancangan murottal otomatis menggunakan mikrokontroller arduino mega 2560," Jurnal Media Infotama, vol.12, pp. 89-99

Syahrul," motor stepper:teknologi, metode dan rangkaian kontrol," Majalah Ilmiah Unikom, Vol.6, No.2

H. Wiryosumatro dan T. Okumura, Teknologi Pengelasan Logam,Volume VIII: Pradnya Paramita Publisher, 2000.

K. Ogata, Modern Control Engineering, Volume V: Pearson Education Publisher, 2004

A. Barnston," correspondence among the correlation [root mean square error] and heidke verification measures; refinement of the heidke score," Notes and Correspondace, vol.1, pp. 699-680

S. Makaridakis, A. Andersen, R. Carbone, R. Fildes, M. Hibon, R. Lewandowski, J. Newton, E. Parzen, and R. Winkler," the accuracy of extrapolation (time series) method: results of a forecasting competition," Jurnal of Forecasting, vol.1, pp. 111-153 